\title{
Correlation Between Turbidimetric and Nephelometric Methods of Measuring C-Reactive Protein in Patients with Unstable Angina or Non-ST Elevation Acute Myocardial Infarction
}

\author{
Luis C. L. Correia, J osé C. Lima, Gary Gerstenblith, Luis P. Magalhães, Agnaluce Moreira, \\ O ctávio Barbosa J r., J uliana Dumet, Luiz Carlos S. Passos, Argemiro D'O liveira Júnior, \\ José Péricles Esteves
}

Salvador, BA, Brazil - Baltimore, MD, USA

\begin{abstract}
Objective - To evaluate the performance of the turbidimetric method of C-reactive protein (CRP) as a measure of low-grade inflammation in patients admitted with nonST elevation acute coronary syndromes (ACS).

Methods - Serum samples obtained at hospital arrival from 68 patients $(66 \pm 11$ years, 40 men), admitted with unstable angina or non-ST elevation acute myocardial infarction were used to measure CRP by the methods of nephelometry and turbidimetry.
\end{abstract}

Results - The medians of C-reactive protein by the turbidimetric and nephelometric methods were $0.5 \mathrm{mg} / \mathrm{dL}$ and $0.47 \mathrm{mg} / \mathrm{dL}$, respectively. A strong linear association existed between the 2 methods, according to the regression coefficient $(\beta=0.75 ; 95 \%$ C.I. $=0.70-0.80)$ and correlation coefficient $(r=0.96 ; P<0.001)$. The mean difference between the nephelometric and turbidimetric CRP was $0.02 \pm 0.91 \mathrm{mg} / \mathrm{dL}$, and $100 \%$ agreement between the methods in the detection of high CRP was observed.

Conclusion - In patients with non-ST elevation ACS, CRP values obtained by turbidimetry show a strong linear association with the method of nephelometry and perfect agreement in the detection of high CRP.

Key words: C-reactive protein, turbidimetric method, acute coronary syndromes

School of Medicine, Federal University of Bahia, Cardiology Division, Portuguese Hospital, Salvador, BA, Brazil, and Cardiology Division, Johns Hopkins Hospital, Baltimore, MD, USA.

Mailing address: Luís Cláudio Lemos Correia - Rua do Tarumã, 90/1002 - 41810-440 Salvador, BA, Brazil - E-mail: lucorrei@terra.com.br
Inflammation plays an important role in the atherosclerotic process ${ }^{1}$, and C-reactive protein (CRP) as an index of low-grade inflammation has been established as an independent predictor of cardiovascular events both in healthy individuals ${ }^{2}$ and in patients with acute coronary syndromes (ACS) ${ }^{3}$.

In stable individuals, values of CRP exceeding $0.3 \mathrm{mg} /$ $\mathrm{dL}$ are associated with a high risk of cardiovascular events ${ }^{4}$. Therefore, a highly sensitive method, such as nephelometry, is necessary to discriminate among such low values of CRP. During ACS, an augmentation of inflammatory activity takes place, and the distribution of CRP values shifts upward ${ }^{5}$. Therefore, turbidimetry, although typically less sensitive than nephelometry, has the potential to be useful in such a patient population.

To evaluate the performance of the turbidimetric method of CRP as an index of low-grade inflammation in subjects with ACS, we correlated measurements by turbidimetry with measurements by nephelometry, both performed on the same plasma samples from patients with unstable angina or non-ST elevation acute myocardial infarction.

\section{Methods}

Patients admitted to the coronary care unit of our hospital because of unstable angina or non-ST elevation acute myocardial infarction between December 2000 and January 2002 were evaluated as study candidates. Inclusion criteria were defined as onset of chest discomfort in the prior 48 hours in patients with ECG changes consisting of transient ST-segment depression $(\geq 0.5 \mathrm{~mm})$ or T wave inversion $(\geq 1.0 \mathrm{~mm})$, and/or positive troponin I (>1.0ng/dL). Infarction at admission was defined by a positive troponin test. Patients with infarction and ST-segment elevation or left bundle-branch block were not included. 
Blood samples obtained at hospital arrival (in the emergency room) were used to simultaneously measure CRP levels by commercially available turbidimetric and nephelometric methods. The turbidimetric method (Biotéctica Indústriae Comércio, Varginha, MG, Brazil) assesses agglutination of latex particles coated with antibody against CRP by quantifying the absorbed $\operatorname{light}^{6}$ (detection limit $>0.4 \mathrm{mg} / \mathrm{dL}$ ). The nephelometric method (Dade Behring Inc., Newark, DE, USA) measures the agglutination of particles by quantifying the scattered light (detection limit $>0.0175 \mathrm{mg} / \mathrm{dL})^{7}$.

Linear associations between the 2 methods of CRP were expressed by regression coefficient $(\beta)$ and correlation coefficient (r). For this analysis, the independent variable was CRP by nephelometry, and the dependent variable was turbidimetric CRP. Because CRP values were not normally distributed in both methods (Shapiro-Wilk test: $\mathrm{P}<$ 0.0001), the nonparametric Spearman correlation coefficient was used. An analysis of the limits of agreement between turbidimetry and nephelometry was also performed as described by Bland and Altman ${ }^{8}$. For this analysis, the difference between the 2 measurements was plotted against their mean. Then, the bias (mean difference between the 2 methods) and thelimits of agreement (2 SD of the difference) were determined.In addition, using the threshold of $1 \mathrm{mg} / \mathrm{dL}$ for high CRP ${ }^{4}$, agreement between the methods was assessed. To correct for the influence of extreme values in the regression and correlation analysis, a secondary analysis was performed after excluding outliers ${ }^{9}$. Such values were defined as at least one of the following: studentized residual $\geq 2$, leverage $>2 \mathrm{p} / \mathrm{n}$, influence on regression coefficient $>2 / \sqrt{ }$ n, influence on regression line $>2 / \sqrt{ } \mathrm{p} / \mathrm{n}$ ( $\mathrm{p}$ : number of parameters $=2$ and $n$ : number of observations $=64$ ). Accordingly, 4 patients were excluded in this secondary analysis.

As secondary end points, risk predictors (TIMI-Risk score, positive troponin, ST-segment depression on admission, ischemia on 48-hour Holter during the acute phase, triple-vessel disease) and the incidence of in-hospital (death, infarction, urgent revascularization) and after discharge (death, infarction, admission with unstable angina)

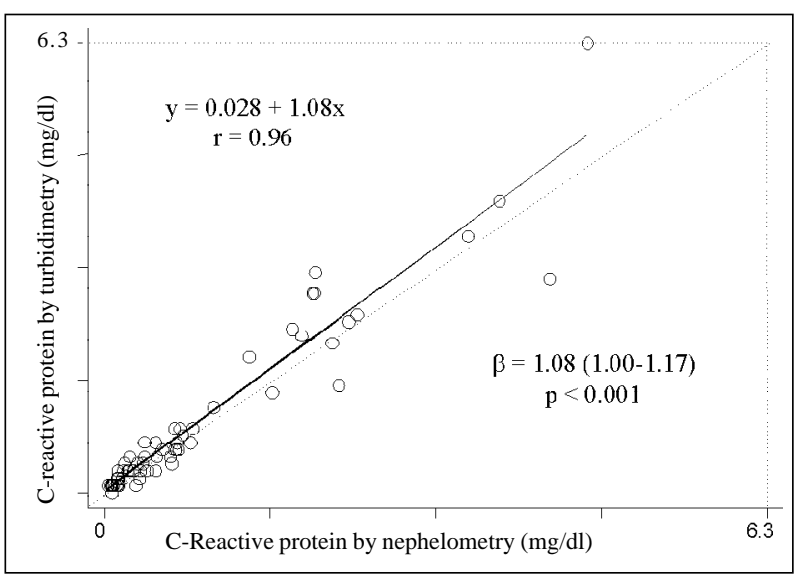

Fig. 1 - Simple linear regression analysis taking CRP by nephelometry as the independent variable and CRP by turbidimetry as the dependent variable. The dashed line indicates the line of identity; the solid line indicates the regression. recurring events were compared between patients with high or low values of turbidimetric CRP, by Pearson's chi-square test or Fisher's exact test for categorical variables and Wilcoxon's Rank-Sum test or the Student $t$ test for continuous variables. For statistical analysis, the software package SPSS version 9.0 was used.

\section{Results}

CRP was measured in 68 consecutive patients, 34 with acute myocardial infarction and 34 with unstable angina. Mean age was $66 \pm 11$ years, 40 were males, 5 were smokers, 24 had diabetes, and 29 used aspirin on a daily basis. Twenty-seven subjects presented with ST-segment depression on admission, 5 had ejection fraction $<45 \%$ on echocardiography, and 16 of the 43 patients who underwent angiography had triple-vessel disease.

Mean time between the onset of clinical symptoms and the collection of the blood sample was $7.8 \pm 7.8$ hours. Measurements of CRP by the turbidimetric method ranged from $0 \mathrm{mg} / \mathrm{dL}$ to $15 \mathrm{mg} / \mathrm{dL}$, with a median of $0.5 \mathrm{mg} / \mathrm{dL}$, and by the nephelometric method from $0.03 \mathrm{mg} / \mathrm{dL}$ to $22 \mathrm{mg} / \mathrm{dL}$, with a median of $0.47 \mathrm{mg} / \mathrm{dL}$. A strong linear association existed between the 2 methods, according to the regression coeffi$\operatorname{cient}(\beta=0.75 ; 95 \%$ C.I. $=0.70-0.80)$ and correlation coeffi$\operatorname{cient}(\mathrm{r}=0.96 ; \mathrm{P}<0.001)$. The strength of the correlation remained after exclusion of the 4 outliers $(\beta=1.08 ; 95 \%$ C.I. $=1.0$ $1.2 ; \mathrm{r}=0.96 ; \mathrm{P}<0.001$ ) (fig. 1). The mean difference between the nephelometric and turbidimetric CRP was $0.02 \pm 0.91 \mathrm{mg} /$ $\mathrm{dL}$ and limits of agreement were $-1.8 \mathrm{mg} / \mathrm{dL}$ and $+1.8 \mathrm{mg} / \mathrm{dL}$. After exclusion of outliers, the mean difference was $0.10 \pm$ $0.37 \mathrm{mg} / \mathrm{dL}$ and limits of agreement were $-0.6 \mathrm{mg} / \mathrm{dL}$ and + $0.8 \mathrm{mg} / \mathrm{dL}$ (fig. 2). Based on a threshold value of $1 \mathrm{mg} / \mathrm{dL}, 100 \%$ agreement existed between the 2 methods in the definition of elevated CRP.

According to both methods of CRP, 19 patients had high CRP $(>1 \mathrm{mg} / \mathrm{dL})$ and 49 had low CRP. Comparison of clinical characteristics and outcomes between these 2 groups are depicted in table I. Patients with high CRP had a

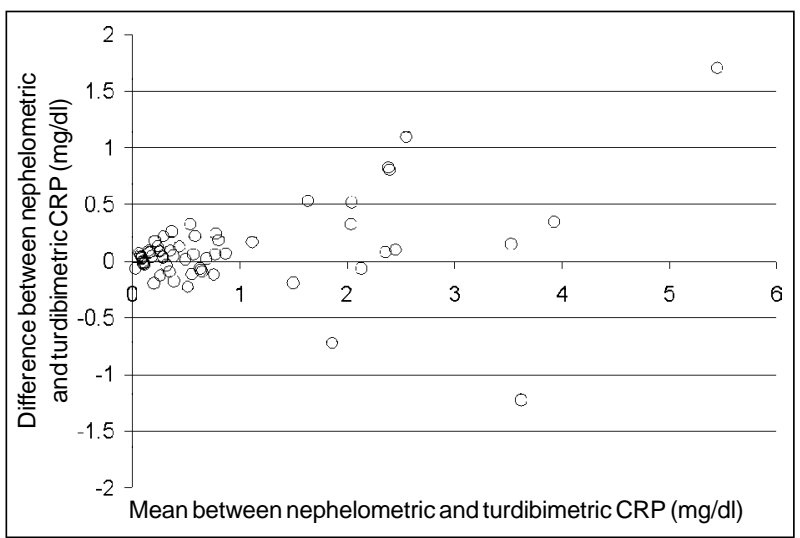

Fig. 2 - Bland-Altman plot of CRP by the turbidimetry and nephelometry. The X axis indicates the arithmetic mean between the values of CRP by turbidimetry and nephelometry in each patient; the $\mathrm{Y}$ axis indicates the difference between the values of CRP by turbidimetry and nephelometry in each patient. 
trend towards longer duration of Holter ischemia in comparison with low CRP patients. Likewise, transient ST-segment depression on admission tended to be more common in patients with high CRP, and a trend towards more patients with triple-vessel disease in the high CRP group was observed. No clear difference was noticeable between the groups in the prevalence of positive troponin at admission or in TIMI-Risk score. Both in-hospital coronary events and events after discharge were similar between patients with high and low CRP.

\section{Discussion}

The present report shows that, in patients with non-ST elevation ACS, CRP levels assessed by the nephelometric and the turbidimetric methods have a strong linear association, represented by a high correlation coefficient and a significant regression coefficient. Although the limits of agreement show that values of the 2 methods are not identical, the ability of turbidimetry in detecting high levels of CRP was identical to that of nephelometry. The nephelometric method is validated by several prospective studies as a marker of cardiovascular risk in patients with ACS ${ }^{3,10-13}$. On the other hand, only 1 study reported the turbidimetric method as a predictor of cardiovascular events in ACS ${ }^{14}$.

The twenty-fifth percentile of CRP is $0.05 \mathrm{mg} / \mathrm{dL}$ in healthy men ${ }^{15}$ and $0.15 \mathrm{mg} / \mathrm{dL}$ in healthy women ${ }^{2}$, and those in the second quartile already have higher cardiovascular risk than subjects in the first quartile. Therefore, a highly sensitive method is necessary to discriminate among such low values. On the other hand, the level of inflammation found in patients with ACS is higher than that in healthy people. For example, the median of high-sensitivity CRP in our study was $0.47 \mathrm{mg} / \mathrm{dL}$ in comparison with $0.15 \mathrm{mg} / \mathrm{dL}$ in the healthy population of The Physician's Health Study ${ }^{15}$. Thus, in patients with ACS, the cutoff value

Table I - Clinical characteristics and outcome of patients with and without elevated turbidimetric C-reactive protein

\begin{tabular}{|lrrr|}
\hline & CRP & $\begin{array}{r}\text { CRP } \\
\text { P }\end{array}$ & P \\
& $1 \mathrm{mg} / \mathrm{dl}$ & $\leq 1 \mathrm{mg} / \mathrm{dl}$ & \\
\hline Number & 19 & 49 & \\
Age & $66 \pm 13$ & $64 \pm 12$ & 0.59 \\
Males & $11(58 \%)$ & $29(59 \%)$ & 0.92 \\
TIMI-Risk (mean) & $3.2 \pm 1.6$ & $3.0 \pm 1.7$ & 0.73 \\
TIMI-Risk $>4$ & $4(21 \%)$ & $11(22 \%)$ & 0.90 \\
Triple-Vessel Disease & $7 / 12^{\dagger}(58 \%)$ & $9 / 31^{\dagger}(29 \%)$ & 0.07 \\
ST Depression & $11(58 \%)$ & $19(39 \%)$ & 0.15 \\
Positive Troponin & $11(58 \%)$ & $23(47 \%)$ & 0.42 \\
LV EF < 45\% & $2(13 \%)$ & $2(5 \%)$ & 0.35 \\
Diabetes & $8(42 \%)$ & $16(33 \%)$ & 0.46 \\
Ischemia on Holter (minutes) & $45 \pm 131$ & $16 \pm 83$ & 0.11 \\
In-hospital Coronary Events & $2(11 \%)$ & $8(16 \%)$ & 0.70 \\
Follow-up Time (months) & $6,9 \pm 3,7$ & $7,2 \pm 3,7$ & 0.84 \\
Coronary Events after Discharge & $3 / 16^{*}(19 \%)$ & $9 / 44 *(21 \%)$ & 1.0 \\
\hline
\end{tabular}

${ }^{\dagger}$ Numerator: patients with coronary lesions > 50\%; denominator: patients who underwent coronariography. ${ }^{*}$ Numerator: patients with events; denominator: patients with follow-up. LVEF: left ventricular ejection fraction that identifies cardiovascular risk is higher than the threshold used in healthy people. According to the recent American Heart Association and Centers for Disease Control and Prevention statement for healthcare professionals ${ }^{4}$, the best cutoff value for patients with ACS is $1 \mathrm{mg} / \mathrm{dL}$, which is within the typical detection limit of turbidimetric methods $(\geq 0.4 \mathrm{mg} / \mathrm{dL})$. This is the basis for the utilization of turbidimetry in the assessment of cardiovascular risk in ACS patients.

A strong correlation between turbidimetric and nephelometric values of CRP was demonstrated by Roberts et al ${ }^{16}$ in a population of blood donors and Hamwi et al ${ }^{17}$ in a nonselected population referred to do the test for different reasons. Roberts et al ${ }^{16}$ demonstrated linearity (systematic error $<10 \%$ ) for values above $0.02 \mathrm{mg} / \mathrm{dL}$ and precision (coefficient of variability <10\%) for values above $0.06 \mathrm{mg} /$ $\mathrm{dL}$ with 9 different turbidimetric methods. Hamwi et al ${ }^{17}$ described coefficient of variability $<5 \%$ above $0.07 \mathrm{mg} / \mathrm{dL}$ with 4 different turbidimetric methods. Mueller at al ${ }^{14}$, although they did not compare the 2 methods, reported in a population of 1042 patients with ACS that CRP level determined on hospital admission by turbidimetry was an independent predictor of short- and long-term mortality. Our study did not primarily evaluate cardiovascular events, but extended the correlation findings of Roberts et $\mathrm{al}^{16}$ and Hamwi et al ${ }^{17}$ to a population with non-ST elevation ACS, also showing perfect agreement in the detection of high CRP. Although risk predictors were more prevalent in those with high CRP, cardiovascular events were not predicted by CRP, possibly due to our small sample size, which makes clinical events a secondary analysis of this report.

High-sensitivity methods of CRP initially used ELISA methodology, as performed in the initial population studies ${ }^{15,18,19}$. This methodology is primarily for research and is not ideal for routine use. Therefore, the nephelometric method was validated for this purpose and is now commercially available. More recently, several turbidimetric CRP assays have been developed and are commercially available. The applicability of turbidimetry to measure CRP in the assessment of low-grade inflammation makes this risk predictor easily available for patients admitted with ACS and facilitates the widespread use of CRP, considering that a nephelometer is not always available. On the other hand, only 1 prospective study ${ }^{14}$ validates $1 \mathrm{mg} / \mathrm{dL}$ as a threshold of risk with turbidimetry, and our limits of agreement analysis showed that values of the 2 methods are not identical. Concurrently, previous studies that compared the nephelometric and turbidimetric methods showed a good correlation, but suggested that better standardization of cutoffs is necessary, because differences existed in CRP values between the methods. Therefore, further studies are necessary to establish whether equal cutoff points are to be used for both methods in ACS patients.

In conclusion, in patients with non-ST elevation ACS, measurements of CRP performed with a turbidimetric method have a strong linear association with the nephelometric method and perfect agreement in the detection of high CRP. 


\section{References}

1. Ross R. Atherosclerosis—an inflammatory disease. N Engl J Med 1999; 340: 115-126.

2. Ridker PM, Hennekens CH, Buring JE, Rifai N. C-reactive protein and other markers of inflammation in the prediction of cardiovascular disease in women. $\mathrm{N}$ Engl J Med 2000; 342: 836-43.

3. Lindahl B, Toss H, Siegbahn A, Venge P, Wallentin L. Markers of myocardial damage and inflammation in relation to long-term mortality in unstable coronary artery disease. FRISC Study Group. Fragminham during Instability in Coronary Artery Disease. N Engl J Med 2000; 343: 1139-47.

4. Pearson TA, Mensah GA, Alexander RW, et al. Markers ofinflammation and cardiovascular disease: application to Clinical and Public Health Practice: a statement for Healthcare Professionals from the Centers for Disease Control and Prevention and the American Heart Association. Circulation 2003; 107: 499-511.

5. Berk BC, Weintraub WS, Alexander RW. Elevation of C-reactive protein in "active" coronary artery disease. Am J Cardiol 1990; 65: 168-72.

6. Sung HJ, Kim JH, Park R, Lee KR, Kwon OH. Evaluation of Denka-Seiken turbidimetric high-sensitivity C-reactive protein assay. Clin Chem Lab Med 2002; 40: 840-5.

7. Rifai N, Tracy RP, Ridker PM. Clinical efficacy of an automated high-sensitivity C-reactive protein assay. Clin Chem 1999; 45: 2136-41.

8. Bland JM, Altman DG. Statistical methods for assessing agreement between two methods of clinical measurement. Lancet 1986; 1: 307-310.

9. Hoaglin DC. Diagnostics. In: Hoaglin DC, Moore DS. Perspectives on Contemporary Statistics., eds., 1992.

10. Benamer H, Steg PG, Benessiano J, et al. Comparison of the prognostic value of Creactive protein and troponin I in patients with unstable angina pectoris. Am J Cardiol 1998; 82: 845-50.

11. Heeschen C,Hamm CW, Bruemmer J, Simoons ML. Predictive value of C-reactive protein and troponin $\mathrm{T}$ in patients with unstable angina: a comparative analysis.
CAPTURE Investigators. Chimeric c7E3 AntiPlatelet Therapy in Unstable angina Refractory to standard treatment trial. J Am Coll Cardiol 2000; 35: 1535-42.

12. Morrow DA, Rifai N, Antman EM, et al. C-reactive protein is a potent predictor of mortality independently of and in combination with troponin $\mathrm{T}$ in acute coronary syndromes: a TIMI 11A substudy. Thrombolysis in Myocardial Infarction. J Am Coll Cardiol 1998; 31: 1460-5.

13. Rebuzzi AG, Quaranta G, Liuzzo G, et al. Incremental prognostic value of serum levels of troponin $\mathrm{T}$ and $\mathrm{C}$-reactive protein on admission in patients with unstable angina pectoris. Am J Cardiol 1998; 82: 715-19.

14. Mueller C, Buettner HJ, Hodgson JM, et al. Inflammation and long-term mortality after non-ST elevation acute coronary syndrome treated with a very early invasive strategy in 1,042 consecutive patients. Circulation 2002; 105: 141215.

15. Ridker PM, Cushman M, Stampfer MJ, Tracy RP, Hennekens CH. Inflammation, aspirin, and the risk of cardiovascular disease in apparently healthy men. N Engl J Med 1997; 336: 973-9.

16. Roberts WL, Moulton L, Law TC, et al. Evaluation of nine automated high-sensitivity C-reactive protein methods: implications for clinical and epidemiological applications. Part 2. Clin Chem 2001; 47: 418-25

17. Hamwi A, Vukovich T, Wagner O, et al. Evaluation of turbidimetric high-sensitivity C-reactive protein assays for cardiovascular risk estimation. Clin Chem 2001; 47: 2044-6.

18. Tracy RP, Lemaitre RN, Psaty BM, et al. Relationship of C-reactive protein to risk of cardiovascular disease in the elderly: results from the Cardiovascular Health Study and the Rural Health Promotion Project. Arteriosclerosis, Thrombosis, and Vascular Biology 1997; 17: 1121-7.

19. Kuller LH, Tracy RP, Shaten J, Meilahn EN. Relation of C-reactive protein and coronary heart disease in the MRFIT nested case-control study. Multiple Risk Factor Intervention Trial. Am J Epidemiol 1996; 144: 537-47. 